\title{
Pengaruh Intrusi Airlaut dan Banjir Pasang (Rob) terhadap Sifat Specific Gravity dan Unit Weight Tanah Lempung Aluvial di Kota Semarang
}

\author{
Dian Agus Widiarso ${ }^{1^{*}}$, Tri Winarno ${ }^{1}$, Wiyatno Haryanto ${ }^{2}$ \\ ${ }^{1}$ Departemen Teknik Geologi, Fakultas Teknik, Universitas Diponegoro, Semarang \\ ${ }^{2}$ PT Vale Indonesia Tbk, Sorowako Kabupaten Luwu Timur, Sulawesi Selatan
}

\begin{abstract}
Abstrak
Terdapat banyak kajian mengenai sifat indeks dan mineralogi lempung pesisir pantai telah dilakukan di berbagai negara sehubungan dengan infrastruktur penting yang dibangun di daerah tersebut. Permasalahan masuknya airlaut ke daratan Kota Semarang yang didominasi oleh lempung terjadi melalui mekanisme intrusi airlaut dan banjir pasang (rob) yang dapat menyebabkan perubahan perilaku tanah lempung. Penelitian dilakukan untuk mengetahui pengaruh banjir pasang dan intrusi airlaut terhadap perilaku tanah lempung khususnya berat jenis (specific gravity) dan berat isi (unit weight). Metode penelitian yang dilakukan adalah pengukuran uji beda Anova nilai specific gravity dan unit weight sampel tanah yang diambil pada kedalaman yang relatif sama dengan mendapatkan perlakuan rob dan tanpa rob. Berdasarkan Uji Anova nilai berat jenis (specific gravity) tanah, nilai $\mathrm{F}$ hitung sebesar 2,601 dengan signifikansi 0,121, berdasarkan Uji Anova nilai berat isi basah (wet unit weight) tanah diketahui nilai $\mathrm{F}$ hitung sebesar 5,572 dengan signifikansi 0,028, dan berdasarkan Uji Anova nilai berat isi kering (dry unit weight) tanah diketahui nilai F hitung sebesar 27,442 dengan signifikansi 0,000 . Nilai specific gravity tidak terdapat perbedaan antara area yang terkena pengaruh rob dan tanpa rob, terdapat perbedaan antara nilai wet unit weight dan dry unit weight pada area yang terkena pengaruh rob dan tanpa rob.
\end{abstract}

Kata kunci: Berat isi; berat jenis; lempung; Semarang.

\begin{abstract}
There are so many studies regarding the index properties and mineralogical of coastal clay deposits that have been carried out in several countries due to the important infrastructures built in the area. The problem of the seawater ingress into the shoreland of Semarang City which is dominated by clay occurs through the mechanism of seawater intrusion and tidal flooding which can cause changes in clay behavior. The research was conducted to determine the influence of tidal flooding and seawater intrusion on clay behavior, especially specific gravity and unit weight. The research method used is the measurement of the Anova difference test, the specific gravity value, and the unit weight of the soil samples taken at the same depth as getting the rob and without rob treatment. Based on the Anova test, the value of the specific gravity of the soil, the calculated $F$ value of 2.601 with a significance of 0.121, based on the Anova test, the value of the wet unit weight of the soil, it is known that the calculated $F$ value of soil dry unit weight, it is known that the $F$ value is 27.442 with a significance and of 0.000. There is no difference in the value of specific gravity between the areas affected by the rob and without the rob, there is a difference between the wet unit weight and dry unit weight values for the areas affected by the rob and without the rob.
\end{abstract}

Keywords:; Unit weight; specific gravity; clay; Semarang.

\footnotetext{
${ }^{*}$ Korespondensi: dianagus@lecturer.undip.ac.id
} 


\section{PENDAHULUAN}

Kota Semarang sebagai ibukota Provinsi Jawa Tengah yang berada di daerah pesisir pantai yang didominasi oleh litologi lempung dan terkonsolidasi normal (Widiarso dkk, 2019) mengalami permasalahan yang rutin terjadi berupa banjir pasang (rob). Banjir pasang atau dalam bahasa Jawa dikenal dengan istilah rob adalah kejadian atau fenomena alam dimana airlaut masuk kewilayah daratan pada waktu permukaan airlaut mengalami pasang (Wahyudi, 2007 dalam Oktavia dkk., 2012). Pasang surut airlaut merupakan suatu gejala fisik yang selalu berulang dengan periode tertentu dan pengaruhnya dapat dirasakan sampai jauh masuk kearah hulu dari muara sungai. Pasang surut airlaut sangat mempengaruhi daerah pesisir dan dapat menyebabkan genangan bahkan banjir. Faktor relief atau tinggi rendahnya kawasan daratan dan sistem drainase berpengaruh terhadap daratan dalam terjadinya rob pada saat terjadi pasang naik.

Banjir pasang airlaut dan selanjutnya disebut dengan rob adalah pola fluktuasi muka airlaut yang dipengaruhi oleh gaya tarik benda-benda angkasa, terutama oleh bulan dan matahari terhadap massa (berat jenis) airlaut di bumi. Rob termasuk bencana banjir yang disebabkan oleh masuknya airlaut ke daratan sebagai akibat dari pasang airlaut yang tinggi (Marfai, 2004 dalam Ikhsyan, 2017). Kejadian bencana alam akan berdampak pada masyarakat dan infrastruktur termasuk kejadian banjir pasang yang terjadi di Semarang Utara menyebabkan kerusakan infrastruktur dan kawasan pemukiman, (Muslim dkk., 2019; Marfai dan King, 2008).Secara umum lempung merupakan bagian penting dari tanah yang sebagian besar melibatkan pelapukan kimia dari mineral pembentuk batuan dan dianggap sebagai tanah berbutir halus dalam ilmu geoteknik. Lempung dapat menunjukkan perilaku keteknikan yang berbeda bergantung pada komposisi mineral dan kimianya dan akan berubah sifat keteknikannya bila bercampur dengan airlaut (Aksoy dkk, 2008).

Kota Semarang mengalami permasalahan yang lain, yakni terjadinya intrusi airlaut. Suhartono dkk. (2013) menunjukkan bahwa pada tahun 1992, airtanah dari sumur bor di sekitar kelurahan Panggung Kidul telah mengalami intrusi airlaut, tetapi seiring bertambahnya waktu sejak tahun 2000 hingga 2013, sumur bor di wilayah Kecamatan
Semarang Utara, Semarang Tengah dan Gayamsari telah terjadi intrusi airlaut dengan tingkat konsentrasi klorida yang cukup tinggi.

Hasil simulasi pada peta sebaran intrusi airlaut menunjukkan bahwa trend terjadinya intrusi airlaut condong dari baratlaut ke arah tenggara. Hatori dkk, 2008 telah melakukan penelitian terhadap penyebaran airtanah payau di Kota Semarang. Penyebaran airtanah payau meliputi Panggung Lor, Panggung Kidul, Kuningan, Dadapsari, Bandarharjo, Tanjung Mas, Kemijen, Rejomulyo, Mlatibaru, Mlatiharjo, Bulu Lor, Bugangan dan Rejosari.

Penelitian mengenai sifat mineralogi dan geoteknik di daerah pesisir pantai dengan dominasi litologi lempung telah dilakukan di berbagai negara karena banyak infrastruktur penting dibangun di daerah tersebut seperti bandar udara, pelabuhan laut dan pusat perbelanjaan (Veerasingam dkk., 2014). Perencanaan kontruksi di daerah Lianyungang China membutuhkan data investigasi batuan asal dan kajian geoteknik mineral lempung daerah tersebut (Liu dkk., 2011). Daerah Changi di Singapura berada pada daerah endapan Kuarter yang tersusun oleh lempung laut lunak sehingga dilakukan penelitian mengenai sifat geoteknik dan mineralogi lempung. Hasil penelitian mengenai nilai kompresi lempung untuk berbagai kedalaman (Bo dkk, 2015).

Keputusan utama dalam proses konstruksi melibatkan pemilihan lokasi yang sesuai dengan kondisi tanah terbaik (Manimaran dkk, 2019). Perencanaan untuk kontruksi menggunakakan perhitungan mekanika tanah yang salah satu parameternya adalah nilai specific gravity dan unit weight. Oleh karena itu penelitian ini dilakukan untuk mengetahui pengaruh banjir pasang dan intrusi airlaut terhadap sifat keteknikan tanah fokus pada nilai specific gravity dan unit weight.

\section{Uji Berat Jenis (Specific Gravity)}

Berat jenis (specific gravity) adalah perbandingan antara berat isi kering butiran tanah dan berat isi air suling pada volume yang sama dengan volume butiran tersebut. Specific gravity ini disimbolkan dengan huruf $\mathrm{G}_{\mathrm{s}}$ dan dapat dihitung dengan persamaan berikut:

$$
\mathrm{G}_{\mathrm{s}}=\gamma_{\mathrm{s}} / \gamma_{\mathrm{w}}
$$




\section{Berat Isi (Unit Weight)}

Berat isi basah $\left(\gamma_{\mathrm{b}}\right)$, adalah perbandingan antara berat butiran tanah termasuk air dan udara (W) dengan volume tanah $(\mathrm{V})$.

$$
\gamma_{\mathrm{b}}=\mathrm{W} / \mathrm{V}
$$

Dengan $\mathrm{W}=\mathrm{W}_{\mathrm{w}}+\mathrm{W}_{\mathrm{s}}+\mathrm{W}_{\mathrm{v}}\left(\mathrm{W}_{\mathrm{v}}=\right.$ berat udara $=$ $0)$. Bila ruang udara terisi oleh air seluruhnya $\left(\mathrm{V}_{\mathrm{a}}=0\right)$, maka tanah menjadi jenuh.

Berat isi kering $\left(\gamma_{\mathrm{d}}\right)$, adalah perbandingan antara berat butiran $\left(\mathrm{W}_{\mathrm{s}}\right)$ dengan volume total $(\mathrm{V})$ tanah.

$$
\gamma_{\mathrm{d}}=\mathrm{W}_{\mathrm{s}} / \mathrm{V}
$$

Berat isi butiran padat $\left(\gamma_{\mathrm{s}}\right)$, adalah perbandingan antara berat butiran padat $\left(\mathrm{W}_{\mathrm{s}}\right)$ dengan volume butiran padat $\left(\mathrm{V}_{\mathrm{s}}\right)$.

$$
\gamma_{\mathrm{s}}=\mathrm{W}_{\mathrm{s}} / \mathrm{V}_{\mathrm{s}}
$$

\section{METODOLOGI}

Lokasi penelitian berada di Kota Semarang Jawa Tengah khususnya pada dataran aluvial berdasarkan Peta Geologi Lembar Magelang dan Semarang, Jawa (Thanden, dkk. 1996).

Analisa kualitatif yang dilakukan berupa deskripsi hasil pengeboran, pengukuran geolistrik dan daya hantar listrik, dan analisa kualitatif daya dukung tanah.

Ketersediaan data yang ada dipisahkan sesuai kebutuhan penelitian yaitu data yang berada di daerah yang terdampak rob tidak terdampak rob yang berada pada daerah aluvium. Lokasi data yang berada di luar aluvium tidak digunakan karena banjir pasang dan intrusi berada pada daerah aluvium. Penelitian dilakukan pada dataran aluvium yang memiliki litologi sama sehingga data hasil lapangan dan uji mekanika tanah dicari sampel tanah yang memiliki kesamaan kedalaman dan terwakili di setiap lokasi.

Pengujian perbedaan tiap parameter pada area yang terdiri atas rob dan tanpa rob dilakukan dengan Uji ANOVA. Anova digunakan sebagai alat analisis untuk menguji hipotesis penelitian dengan menilai adakah perbedaan antar kelompok (Arifin, 2017). Uji ANOVA tersebut dilakukan untuk menguji perbedaan parameter dalam berbagai lokasi dengan tahapan sebagai berikut:

a. Penentuan hipotesis

$\mathrm{H}_{0}: \mathrm{X}_{1}=\mathrm{X}_{2}=\mathrm{X}_{3}$

Tidak terdapat perbedaan antara area rob dan tidak rob
$\mathrm{H}_{1}: \mathrm{X}_{1} \neq \mathrm{X}_{2} \neq \mathrm{X}_{3}$

Terdapat perbedaan antara area rob dan tidak rob

b. Penentuan tingkat keyakinan

Pengujian hipotesis dilakukan pada tingkat keyakinan 95 persen dan alpha $(\alpha)=5$ persen.

c. Penentuan kriteria pengujian

$\mathrm{H}_{0}$ diterima jika nilai Signifikansi (Sig) $>0,05$

$\mathrm{H}_{0}$ ditolak jika nilai Signifikansi (Sig) $<0,05$

\section{HASIL}

Pengumpulan data sekunder, berupa hasil penelitian terdahulu terkait geologi regional, data penyelidikan geologi teknik dari 31 data bor yang memiliki hasil uji laboratorium yang dapat dilakukan uji beda antar variabel. Uji beda dilakukan pada sampel tanah yang diambil pada kedalaman yang sama dan dibandingkan yakni untuk parameter specific gravity dan unit weight, serta data penyelidikan rob, data pengukuran geolistrik, dan daya hantar listrik.

Data input untuk uji F pada specific gravity ditunjukan di dalam Tabel 1. Berdasarkan Tabel 1 dapat diketahui hasil pengukuran specific gravity pada area rob berkisar antara 1,59 sampai dengan 2,66 dengan rata-rata 2,47. Hasil pengukuran specific gravity pada area tidak terkena rob berkisar antara 2,52 sampai dengan 2,74 dengan rata-rata 2,61. Data input untuk uji $\mathrm{F}$ wet unit weight ( $\gamma$ Wet) ditunjukkan oleh Tabel 2.

Berdasarkan Tabel 2 dapat diketahui hasil pengukuran wet unit weight ( $\gamma$ Wet) pada area area rob berkisar antara 1,48 sampai dengan 1,74 dengan rata-rata 1,58. Hasil pengukuran wet unit weight ( $\gamma$ Wet) pada area tidak rob berkisar antara 1,53 sampai dengan 1,76 dengan rata-rata 1,66.

Data input untuk uji $\mathrm{F}$ Berat Isi $\gamma$ Dry ditunjukkan oleh Tabel 3. Berdasarkan Tabel 3 dapat diketahui hasil pengukuran dry unit weight ( $\gamma$ Dry) pada area rob berkisar antara 0,85 sampai dengan 1,16 dengan rata-rata 0,95 . Hasil pengukuran dry unit weight $(\gamma$ Dry) pada area tidak rob berkisar antara 1,00 sampai dengan 1,42 dengan rata-rata 1,20 . 
Tabel 1. Data input uji F specific gravity

\begin{tabular}{cccc}
\multicolumn{4}{c}{ Specific Gravity } \\
\hline \multicolumn{3}{c}{ Rob } & \multicolumn{3}{c}{ Tidak rob } \\
\hline KL1 & 2,59 & BK1 & 2,65 \\
PTM1 & 2,61 & BK2 & 2,52 \\
PTM2 & 2,60 & BL1 & 2,74 \\
PTM3 & 2,60 & BL2 & 2,73 \\
PTM4 & 1,59 & BL3 & 2,62 \\
PLN & 2,66 & BS1 & 2,62 \\
TL1 & 2,51 & BS2 & 2,61 \\
TL2 & 2,51 & BS3 & 2,62 \\
TL3 & 2,51 & KG1 & 2,52 \\
TL4 & 2,50 & KG2 & 2,55 \\
Rata-rata & 2,47 & KG3 & 2,57 \\
Minimal & 1,59 & KG4 & 2,59 \\
Maksimal & 2,66 & KG5 & 2,56 \\
& & KG6 & 2,60 \\
& & Rata-rata & 2,61 \\
& & Minimal & 2,52 \\
& & Maksimal & 2,74 \\
\hline
\end{tabular}

Tabel 2. Data input uji F wet unit weight

\begin{tabular}{llll}
\multicolumn{4}{c}{ Berat isi $\boldsymbol{\gamma}$ Wet } \\
\hline \multicolumn{3}{c}{ Rob } & \multicolumn{2}{c}{ Tidak rob } \\
\hline KL1 & 1,74 & BK1 & 1,69 \\
PTM1 & 1,61 & BK2 & 1,70 \\
PTM2 & 1,59 & BL1 & 1,70 \\
PTM3 & 1,58 & BL2 & 1,76 \\
PTM4 & 1,59 & BL3 & 1,67 \\
PLN & 1,71 & BS1 & 1,72 \\
TL1 & 1,51 & BS2 & 1,69 \\
TL2 & 1,49 & BS3 & 1,71 \\
TL3 & 1,48 & KG1 & 1,56 \\
TL4 & 1,48 & KG2 & 1,53 \\
Rata-rata & 1,58 & KG3 & 1,56 \\
Minimal & 1,48 & KG4 & 1,63 \\
Maksimal & 1,74 & KG5 & 1,63 \\
& & KG6 & 1,60 \\
& & Rata-rata & 1,66 \\
& & Minimal & 1,53 \\
& & Maksimal & 1,76 \\
\hline & & &
\end{tabular}

\section{PEMBAHASAN}

Pengujian perbedaan specific gravity, wet unit weight ( $\gamma$ Wet) dan dry unit weight ( $\gamma$ Dry) pada area rob dan tanpa rob dilakukan dengan Uji Anova. Berdasarkan Tabel 4 dapat diketahui nilai $F$ hitung sebesar 2,601 dengan signifikansi 0.121. Jadi F hitung berada di daerah penerimaan $\mathrm{HO}$ (Sig >0,05), artinya tidak terdapat perbedaan antara specific gravity pada area rob dan tidak rob.

Tabel 3. Data input uji F dry unit weight ( $\gamma$ Dry)

\begin{tabular}{cccc}
\hline \multicolumn{4}{c}{ Berat isi $\boldsymbol{\gamma}$ Dry } \\
\hline Rob & \multicolumn{3}{c}{ Tidak rob } \\
\hline KL1 & 1,12 & BK1 & 1,24 \\
PTM1 & 0,99 & BK2 & 1,23 \\
PTM2 & 0,92 & BL1 & 1,37 \\
PTM3 & 0,89 & BL2 & 1,42 \\
PTM4 & 0,87 & BL3 & 1,36 \\
PLN & 1,16 & BS1 & 1,19 \\
TL1 & 0,93 & BS2 & 1,21 \\
TL2 & 0,88 & BS3 & 1,19 \\
TL3 & 0,85 & KG1 & 1,07 \\
TL4 & 0,91 & KG2 & 1,00 \\
Rata-rata & 0,95 & KG3 & 1,06 \\
Minimal & 0,85 & KG4 & 1,16 \\
Maksimal & 1,16 & KG5 & 1,18 \\
& & KG6 & 1,16 \\
& & Rata-rata & 1,20 \\
& & Minimal & 1,00 \\
& & Maksimal & 1,42 \\
\hline \multicolumn{3}{c}{}
\end{tabular}

Tabel 4. Hasil uji Anova specific gravity.

\begin{tabular}{lrrrrr}
\hline & $\begin{array}{c}\text { Sum of } \\
\text { Squares }\end{array}$ & df & $\begin{array}{c}\text { Mean } \\
\text { Square }\end{array}$ & F & Sig. \\
\hline $\begin{array}{l}\text { Between } \\
\text { Groups }\end{array}$ & .112 & 1 & .112 & 2.601 & .121 \\
$\begin{array}{l}\text { Within } \\
\text { Groups }\end{array}$ & .950 & 22 & .043 & & \\
Total & 1.062 & 23 & & & \\
\hline
\end{tabular}

Tabel 5. Hasil uji Anova wet unit weigth ( $\gamma \mathrm{Wet})$

\begin{tabular}{lrrrrr}
\hline & $\begin{array}{c}\text { Sum of } \\
\text { Squares }\end{array}$ & $\boldsymbol{d f}$ & $\begin{array}{c}\text { Mean } \\
\text { Square }\end{array}$ & $\boldsymbol{F}$ & Sig. \\
\hline $\begin{array}{l}\text { Between } \\
\text { Groups }\end{array}$ & .035 & 1 & .035 & 5.572 & .028 \\
$\begin{array}{l}\text { Within } \\
\text { Groups } \\
\text { Total }\end{array}$ & .139 & 22 & .006 & & \\
\hline
\end{tabular}


Tabel 6. Hasil uji Anova dry unit weight ( $\gamma$ Dry)

\begin{tabular}{lrrrrr}
\hline & $\begin{array}{c}\text { Sum of } \\
\text { Squares }\end{array}$ & df & $\begin{array}{c}\text { Mean } \\
\text { Square }\end{array}$ & F & Sig. \\
\hline $\begin{array}{l}\text { Between } \\
\text { Groups }\end{array}$ & .366 & 1 & .366 & 27.442 & .000 \\
$\begin{array}{l}\text { Within } \\
\text { Groups }\end{array}$ & .293 & 22 & .013 & & \\
Total & .659 & 23 & & & \\
\hline
\end{tabular}

Tabel 5 menunjukkan nilai $\mathrm{F}$ hitung sebesar 5,572 dengan signifikansi 0,028. Jadi, F hitung berada di daerah penolakan $\mathrm{H}_{0}(\mathrm{Sig}<0,05)$, artinya terdapat perbedaan antara wet unit weight $(\gamma$ Wet) pada area rob dan tidak rob.

Berdasarkan Tabel 6 dapat diketahui nilai $\mathrm{F}$ hitung sebesar 27,442 dengan signifikansi 0,000. Jadi $\mathrm{F}$ hitung berada di daerah penolakan $\mathrm{H}_{0}$ $($ Sig $<0,05)$, artinya terdapat perbedaan antara dry unit weight ( $\gamma$ Dry) pada area rob dan tidak rob.

\section{KESIMPULAN}

Hasil uji satistik pada beberapa parameter geoteknik (specific gravity dan unit weight) menunjukkan adanya perbedaan perilaku pada salah satu parameter tanah antara tanah yang dipengaruhi oleh rob serta tanah yang tidak dipengaruhi oleh rob. Setelah melalui proses verifikasi menggunakan uji statistik melalui pendekatan uji beda Anova pada variabel uji berupa nilai specific gravity, wet unit weigth $(\gamma$ Wet) dan dry unit weight ( $\gamma$ Dry), hal tersebut menunjukkan bahwa parameter specific gravity tidak memiliki pebedaan yang signifikan antar lokasi terdampak rob dengan lokasi tidak terdampak rob, sedangkan pada parameter uji wet unit weight $(\gamma \mathrm{Wet})$ dan dry unit weight $(\gamma$ Dry) memiliki pebedaan yang signifikan antar lokasi terdampak rob dengan lokasi tidak terdampak rob. Hal tersebut dapat disimpulkan bahwa peristiwa intrusi airlaut dan banjir pasang (rob) dapat mempengaruhi nilai parameter unit weigth tanah, namun tidak berpengaruh secara signifikan terhadap nilai parameter specific gravity.

\section{UCAPAN TERIMA KASIH}

Tulisan ini adalah bagian dari penelitian Riset Pengembangan dan Penerapan (RPP) Sumber Dana Selain APBN Universitas Diponegoro Tahun Anggaran 2020. Penulis berterima kasih kepada semua pihak yang telah mendukung dan membantu selama proses penelitian..

\section{DAFTAR PUSTAKA}

Aksoy, Y. Y., Kaya, A., Oren, A. H., 2008. Seawater effect on consistency limits and compressibility characteristics of clays. Engineering Geology 102, hal 54-61.

Arifin, J., 2017, Spss 24 Untuk Penelitian Dan Skripsi, Elex Media Komputindo.

Bo, M. W., Arulrajah, A., Sukmak, P., dan Horpibulsuk, S., 2015. Mineralogy and Geotechnical Properties of Singapore Marine Clay at Changi. Soils and Foundation 55, hal $600-613$.

Hatori, C. A., Hendrayana, H. dan Putra, D. P. E., 2008. Studi Kerentanan Airtanah Terhadap Intrusi Airlaut di Kota Semarang, Jawa Tengah. http://www.academia.edu/1049978.

Ikhsyan N., Muryani C., Rintayati P., 2017. Analisis Sebaran, Dampak Dan Adaptasi Masyarakat Terhadap Banjir Rob Di Kecamatan Semarang Timur Dan Kecamatan Gayamsari Kota Semarang. Jurnal Geoeco, 3(2), hal 145-156.

Liu, S. Y., Shao, G. H., Du, Y. J., Cai, G. J., 2011, Depositional and Geotechnical properties of Marine Clays in Lianyungang, China. Engineering Geology 121, hal 66 74.

Manimaran, A., Seenu, S., Ravichandra, P. Tn, 2019. Stimulation Behaviour Study on Clay Treated with Ground Granulated Blast Slag and Groundnutshell Ash. International Journal of Engineering (32)5, hal 673-678.

Marfai, M A dan King L. 2008. Potential Vulnerability Implications If Coastalinundation Due Sea Level Rise For The Coastal Zone Of Semarang City, Indonesia. Jurnal Enviromental Geology, 54, hal 1235-1245.

Muslim, D, Haerani E., Muslim F. N. dan Muslim G. O., 2019, Toward the Safe Liveable Built Environment around CiletuhPalabuhanratu Geopark Area in Sukabumi Regency, Indonesia, IOP Conf. Series: Earth and Environmental Science 248, (2019) 012036.

Oktavia M. I., Parman S., Setyowati D. L., 2012. Analisis Sebaran Genangan Pasang Air Laut (Rob) Berdasarkan High Water Level Dan Dampaknya Pada Penggunaan Lahan Di 
Ke 7 camatan Semarang Utara, Jurnal Geo Image 1(1).

Suhartono, E., Purwanto dan Suripin, 2013. Model Intrusi Airlaut Terhadap Airtanah Pada Akuifer di Kota Semarang, Prosiding Seminar Nasional Pengelolaan Sumberdaya Alam dan Lingkungan.

Thanden, R. E., Sumadirdja, H., Richards, P. W., dan Sutisna, K., 1996. Peta Geologi Lembar Magelang dan Semarang, Jawa skala 1:100.000. Bandung: Pusat Survey Geologi.
Veerasingam, S., Venkatachalapathy, R., Ramkumar, T., 2014, Distribution of Clay Minerals in marine Sediments Off Chennai, Bay of Bengal, India: Indicators of Sediment Sources and Transport Processes. International Journal of Sediment Research 29(1), hal. 11-2.

Widiarso, D. A., Haryanto, W., Muslim, D., Zakaria, Z. dan Iskandarsyah, T. Y., 2019, Potential Consolidation Settlement Due to Load Stresses of Building Structures, International Journal of GEOMATE, 1(60), hal 204-210. 